\section{Frailty syndrome and sarcopenia among rural older adults in West Bengal, India: a cross-sectional study}

\author{
Sayani Das, M Phil; Susmita Mukhopadhyay, PhD; Barun Mukhopadhyay, PhD
}

\begin{abstract}
Background. Frailty is a multidimensional syndrome. Sarcopenia plays an essential role in the early diagnosis and prevention of frailty syndrome. Therefore, we examined the association of frailty syndrome with sarcopenia among community-dwelling rural older adults in West Bengal.

Methods: This cross-sectional survey was conducted between October 2018 and January 2020 in 510 (230 men and 280 women) older adults aged $\geq 60$ years who had lived for $>10$ years in the selected villages of Pancharul Gram Panchayat, Udaynarayanpur Block of Howrah District, West Bengal, India. Participants were assessed for frailty syndrome and sarcopenia as well as cognitive impairment, social support, history of fall, and nutritional status by a single investigator. Frailty syndrome was assessed using the modified Physical Frailty Phenotype Scale. Frailty is defined as a display of $\geq 3$ of five physiological deficits: low weight, low gait speed, reduced muscle strength, exhaustion, and low physical activity. Sarcopenia was assessed using the Asian Working Group on Sarcopenia 2014 consensus by measuring dominant hand grip strength, gait speed, and skeletal muscle mass index.
\end{abstract}

Results: Of the 510 participants, $44(8.6 \%)$ were both frail and sarcopenic, 88 (17.3\%) were frail only, $16(3.1 \%)$ were sarcopenic only, and $362(71.0 \%)$ were non-frail and non-sarcopenic. The prevalence of frailty syndrome was $25.9 \%$, whereas the prevalence of sarcopenia was $11.8 \%$. Compared with non-frail participants, frail participants were six times (adjusted $\mathrm{OR}=6.42, \mathrm{p}<0.01$ ) more likely to be sarcopenic after adjusting for age, marital status, educational level, occupational work, cognitive impairment, social support, history of fall, and nutritional status.

Conclusion: Sarcopenia affects the development of frailty syndrome.

Key words: Aged; Frailty; India; Rural population; Sarcopenia

\section{ORIGINAL ARTICLE}

Biological Anthropology Unit, Indian

Statistical Institute, Kolkata, India

Correspondence to: Sayani Das, Biological Anthropology Unit, Indian Statistical Institute, Kolkata-700108, West Bengal, India.Email: das.sayani6@gmail.com

\section{BACKGROUND}

Population ageing is a major public health concern. The increase in life expectancy contributes to the decline of quality of life. ${ }^{1}$ The developing countries will see the greatest change in the numbers of the aged. ${ }^{2}$ From 2013 to 2100, half of the world's population increase will occur in Nigeria, India, Tanzania, Congo, Uganda, and Ethiopia. ${ }^{3}$ In 2011, $8.6 \%$ of India's population was $>60$ years, and the percentage is expected to reach $20 \%$ by $2050 .{ }^{4}$ In India, $71 \%$ ( $>73$ million) of the older populations live in rural areas. ${ }^{4}$ Demographic changes affect the health system, socio-economic development, 
cultural norms, and political contexts of India. ${ }^{5}$

Frailty syndrome is a multidimensional geriatric syndrome associated with the loss of physical and/or psychosocial functions resulting in cognitive decline, disability, falls, hospitalisation, and even death. ${ }^{6}$ India has the highest incidence of frailty syndrome among the six low- and middle-income countries (China, Ghana, Mexico, Russia, and South Africa). ${ }^{7}$ Residents of West Bengal have the highest mean frailty score than do the residents of other Indian states, and rural residents of West Bengal are at significantly higher risk of frailty than are their urban counterparts. ${ }^{8}$ Frailty syndrome can be reversed, especially in mild stages. ${ }^{9}$

Sarcopenia is defined as an age-related decrease of muscle mass and considered a precursor syndrome or the physical manifestation of frailty. ${ }^{10,11}$ In 2010, the European Working Group on Sarcopenia in Older People defined sarcopenia as a geriatric condition characterised by progressive and generalised loss of skeletal muscle mass, strength, and function. ${ }^{12}$ The prevalence of sarcopenia is highest in India among the countries considered (China, Ghana, Mexico, Poland, Russia, South Africa, and Spain). ${ }^{13}$ Therefore, the present study aims to determine the association of frailty syndrome with sarcopenia among community-dwelling rural older adults in West Bengal.

\section{METHODS}

This cross-sectional study was approved by the ethics committee of Indian Statistical Institute, Kolkata, India (reference: ISI-IEC/2018/10/02) and was conducted between October 2018 and January 2020. Written informed consent was obtained from each participant. We approached 623 older adults aged $\geq 60$ years who had lived for $>10$ years in the selected villages of Pancharul Gram Panchayat, Udaynarayanpur Block of Howrah District, West Bengal, India. Those with physical or mental disability were excluded, as were those whose age could not be verified. Of them, 510 (230 men and 280 women) participants were included. Participants' age, sex, marital status, family pattern, education level, and occupational work were recorded. Participants were assessed for frailty syndrome and sarcopenia as well as cognitive impairment, social support, history of fall, and nutritional status by a single investigator.
Frailty syndrome was assessed using the modified Physical Frailty Phenotype Scale. ${ }^{6}$ Frailty is defined as a display of $\geq 3$ of five physiological deficits: low weight, low gait speed, reduced muscle strength, exhaustion, and low physical activity. Low weight is defined as the lowest quintile in the body mass index (adjusted for sex). Low gait speed is defined as the lowest quintile in the 4-m walk (adjusted for sex and height). Reduced muscle strength is defined as the lowest quintile in dominant hand grip strength (adjusted for sex and body mass index) measured using a dynamometer (Jamar Hydraulic Hand Dynamometer). Exhaustion is defined as having a response of 'a little' or 'not at all' energy for daily activities when asked. Low physical activity (energy expenditure) is defined as below the cut-off of the Global Physical Activity Questionnaire. ${ }^{14}$

Sarcopenia was assessed using the Asian Working Group on Sarcopenia 2014 consensus ${ }^{15}$ by measuring dominant hand grip strength, gait speed, and skeletal muscle mass index (FIGURE). The latter is calculated by dividing the appendicular skeletal muscle mass $(\mathrm{kg})$ by the square of the height $\left(\mathrm{m}^{2}\right)$. Appendicular skeletal muscle mass is calculated based on the anthropometric equation: ${ }^{16}\{0.193 \times$ weight $(\mathrm{kg})+0.107 \times$ height $(\mathrm{cm})-4.157 \times$ sex $(\operatorname{man}=1$, woman $=2)-0.037 \times$ age $(y)-2.63$.

Cognitive impairment was assessed using the Bangla Adaptation of Mini-Mental State

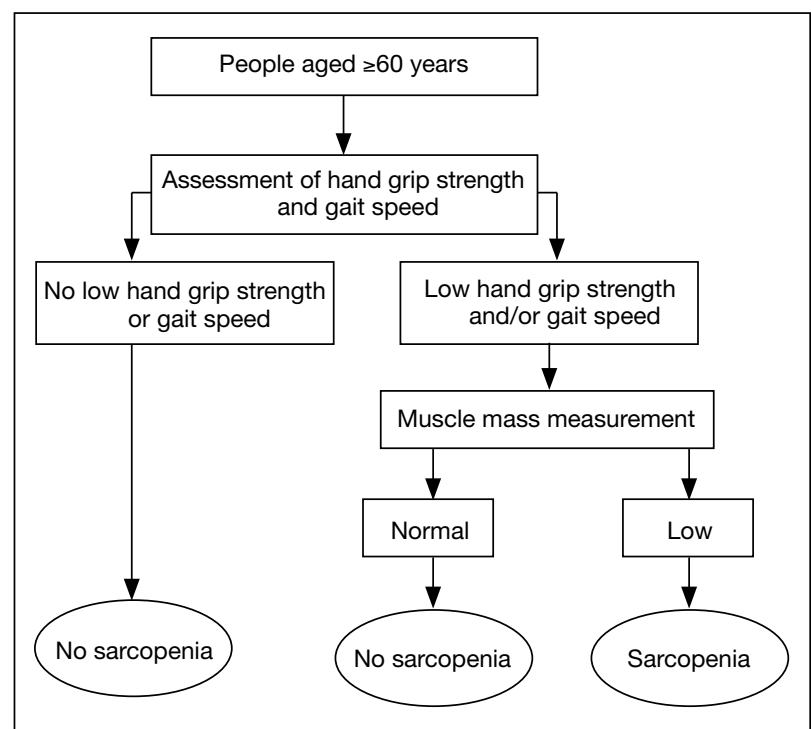

FIGURE. Sarcopenia is determined by measuring dominant hand grip strength, gait speed, and skeletal muscle mass index. 
Examination scale. ${ }^{17}$ Social support was assessed using the Multidimensional Scale of Perceived Social Support. ${ }^{18}$ History of fall in the past 6 months was recorded. Nutritional status was assessed using the Mini Nutritional Assessment scale. ${ }^{19}$

The Chi-squared test was used to compare the frail and non-frail groups; significant variables were entered as independent variables in the multivariate binomial logistic regression model to determine the association of frailty syndrome with sarcopenia. A p value of $<0.05$ was considered statistically significant. Statistical analysis was performed using SPSS (Windows version 20; IBM Corp, Armonk [NY], US).

\section{RESULTS}

Of the 510 participants, 44 (8.6\%) were both frail and

TABLE 1

Characteristics of frail and non-frail participants

\begin{tabular}{|c|c|c|c|c|}
\hline & Total $(n=510)$ & Frail $(n=132)$ & Non-frail $(n=378)$ & $\mathrm{p}$ Value \\
\hline Age, y & & & & $<0.001$ \\
\hline $60-69$ & 246 (48.2) & $20(15.2)$ & $226(59.8)$ & \\
\hline $70+$ & 264 (51.8) & $112(84.8)$ & $152(40.2)$ & \\
\hline Sex & & & & 0.92 \\
\hline Male & $230(45.1)$ & $60(45.5)$ & $170(45.0)$ & \\
\hline Female & 280 (54.9) & $72(54.5)$ & 208 (55.0) & \\
\hline Marital status & & & & $<0.001$ \\
\hline Married & $283(55.5)$ & $55(41.7)$ & $228(60.3)$ & \\
\hline Widowed & 227 (44.5) & 77 (58.3) & $150(39.7)$ & \\
\hline Family & & & & 0.57 \\
\hline Joint & 375 (73.5) & $100(75.8)$ & 275 (72.8) & \\
\hline Single/nuclear & $135(26.5)$ & $32(24.2)$ & 103 (27.2) & \\
\hline Education & & & & 0.02 \\
\hline$\geq$ Primary & $87(17.1)$ & $14(10.6)$ & 73 (19.3) & \\
\hline$<$ Primary & 423 (82.9) & $118(89.4)$ & $305(80.7)$ & \\
\hline Occupational work & & & & $<0.001$ \\
\hline Yes & 178 (34.9) & $20(15.2)$ & $158(41.8)$ & \\
\hline No & $332(65.1)$ & $112(84.8)$ & 220 (58.2) & \\
\hline Social support & & & & $<0.001$ \\
\hline High/moderate & $252(49.4)$ & $89(67.4)$ & $163(43.1)$ & \\
\hline Low & $258(50.6)$ & $43(32.6)$ & 215 (56.9) & \\
\hline History of fall & & & & $<0.001$ \\
\hline No & $385(75.5)$ & $83(62.9)$ & 302 (79.9) & \\
\hline Yes & $125(24.5)$ & $49(37.1)$ & $76(20.1)$ & \\
\hline Nutritional status & & & & $<0.001$ \\
\hline Non-malnourished & $196(38.4)$ & $18(13.6)$ & $178(47.1)$ & \\
\hline Malnourished & $314(61.6)$ & $114(86.4)$ & $200(52.9)$ & \\
\hline Cognitive impairment & & & & $<0.001$ \\
\hline No & 305 (59.8) & 58 (43.9) & 247 (65.3) & \\
\hline Yes & 205 (40.2) & $74(56.1)$ & $131(34.7)$ & \\
\hline Sarcopenia & & & & $<0.001$ \\
\hline Yes & $60(11.8)$ & 44 (33.3) & $16(4.2)$ & \\
\hline No & 450 (88.2) & $88(66.7)$ & 362 (95.8) & \\
\hline
\end{tabular}


sarcopenic, 88 (17.3\%) were frail only, 16 (3.1\%) were sarcopenic only, and 362 (71.0\%) were non-frail and non-sarcopenic. The prevalence of frailty syndrome was $25.9 \%$, whereas the prevalence of sarcopenia was $11.8 \%$. Frailty syndrome was associated with age, marital status, educational status, occupational work, cognitive impairment, social support status, history of fall, nutritional status, and sarcopenia (TABLE 1). $44(33.3 \%)$ of 132 frail participants were sarcopenic, whereas $16(4.2 \%)$ of 378 non-frail participants were sarcopenic $(p<0.001)$. Frail syndrome was more prevalent in those aged $\geq 70$ years (odds ratio $[\mathrm{OR}]=8.3, \mathrm{p}<0.001)$, widowed $(\mathrm{OR}=2.13$, $\mathrm{p}<0.001)$, with less than primary education $(\mathrm{OR}=2.02$, $\mathrm{p}=0.024)$, with low social support $(\mathrm{OR}=0.366$, $\mathrm{p}<0.001)$, without occupational work $(\mathrm{OR}=4.02$, $\mathrm{p}<0.001)$, malnourished $(\mathrm{OR}=5.64, \mathrm{p}<0.001)$, with cognitive impairment $(\mathrm{OR}=2.41, \mathrm{p}<0.001)$, and with a history of at least one fall in the past 6 months $(\mathrm{OR}=2.35, \mathrm{p}<0.001)$ [TABLE 2]. In multivariate binary logistic regression analysis, compared with nonfrail participants, frail participants were six times (adjusted OR=6.42, $\mathrm{p}<0.001$ ) more likely to be sarcopenic after adjusting for age, marital status, educational level, occupational work, cognitive impairment, social support, history of fall, and nutritional status (TABLE 2).

\section{DISCUSSION}

Frailty syndrome and sarcopenia are two associated but distinct conditions that share common sociodemographic, physical, social, and cognitive covariates. Frailty is associated with ageing., ${ }^{7,21}$ Those with frailty are more likely to be widows and less educated. ${ }^{22,23}$ Lower level of education is associated with less income and wealth, which are correlated with poorer health. Lack of companionship negatively affects health and well-being. Active participation in occupational work and having social support play an important role among communitydwelling older adults. Fall is a common cause of injury and associated with frailty syndrome. ${ }^{24}$ Undernutrition is associated with frailty and sarcopenia. ${ }^{25}$ Cognitive impairment is associated with frailty syndrome. ${ }^{26}$

Among elderly nursing home residents in Belgium, the prevalence of sarcopenia was $47 \%$ among those who were frail. ${ }^{27}$ In a German university hospital, $19 \%$ of patients aged $\geq 70$ years
TABLE 2

Association of frailty syndrome with sarcopenia

\begin{tabular}{|c|c|c|}
\hline & $\begin{array}{c}\text { Odds ratio } \\
\text { (confidence interval) }\end{array}$ & $p$ Value \\
\hline Sarcopenia & & $<0.001$ \\
\hline Yes & $\begin{array}{l}11.31(6.10-20.98) \\
6.42(3.10-13.30)^{\star}\end{array}$ & \\
\hline No & Reference & \\
\hline Age, y & & $<0.001$ \\
\hline $70+$ & 8.33 (4.96-13.98) & \\
\hline $60-69$ & Reference & \\
\hline Marital status & & $<0.001$ \\
\hline Widow & $2.13(1.42-3.18)$ & \\
\hline Married & Reference & \\
\hline Education & & 0.024 \\
\hline$<$ Primary & $2.02(1.10-3.71)$ & \\
\hline$\geq$ Primary & Reference & \\
\hline Occupational work & & $<0.001$ \\
\hline No & 4.02 (2.40-6.75) & \\
\hline Yes & Reference & \\
\hline Social support & & $<0.001$ \\
\hline Low & $0.366(0.24-0.56)$ & \\
\hline High/ moderate & Reference & \\
\hline History of fall & & $<0.001$ \\
\hline Yes & $2.35(1.52-3.62)$ & \\
\hline No & Reference & \\
\hline Nutritional status & & $<0.001$ \\
\hline Malnourished & 5.64 (3.30-9.64) & \\
\hline Non-malnourished & Reference & \\
\hline Cognitive impairment & & $<0.001$ \\
\hline Yes & $2.41(1.61-3.60)$ & \\
\hline No & Reference & \\
\hline
\end{tabular}

* After adjusting for age, marital status, education, working, social support, history of fall, nutritional status, and cognitive impairment

had both frailty and sarcopenia. ${ }^{28}$ In our West Bengal rural community-dwelling participants, $4.2 \%$ of non-frail participants had sarcopenia, 33.3\% of frail participants had sarcopenia, and $8.6 \%$ of participants had both frailty and sarcopenia. Compared with non-frail participants, frail participants were six times more likely to be sarcopenic after adjusting for confounding factors. Among Japanese communitydwelling older women aged $\geq 65$ years, frail individuals were more likely to have sarcopenia (OR=19.1, 95\% confidence interval $[\mathrm{CI}]=3.73-98.0)$ than non-frail individuals. ${ }^{29}$ In the Toledo Study of Healthy Aging, among community-dwelling older 
adults aged $\geq 65$ years, frailty was associated with sarcopenia according to the European Working Group on Sarcopenia in Older People criteria $(\mathrm{OR}=1.67,95 \% \mathrm{CI}=0.95-2.96)$, the Foundation for the National Institutes of Health (FNIH) criteria (OR=10.61, 95\% CI=5.8-19.4), and the standardised FNIH criteria $(\mathrm{OR}=6.63,95 \% \mathrm{CI}=3.5-12.53) .{ }^{30}$

As frailty syndrome is associated with sarcopenia, early diagnosis and prevention of sarcopenia is needed for better management of frailty syndrome, particularly in West Bengal where its prevalence of frailty syndrome is the highest among Indian states. ${ }^{8}$ However, studies with a larger sample size are warranted to validate our findings in different communities and to develop community-specific strategies for healthy ageing in India. The Fried frailty criteria and the Asian Working Group for Sarcopenia criteria are widely used and allow us to compare our results with other studies.

\section{CONCLUSION}

Sarcopenia affects the development of frailty syndrome.

\section{CONTRIBUTORS}

All authors designed the study, acquired the data, analysed the data, drafted the manuscript, and critically revised the manuscript for important intellectual content. All authors had full access to the data, contributed to the study, approved the final version for publication, and take responsibility for its accuracy and integrity.

\section{CONFLICTS OF INTEREST}

All authors have disclosed no conflicts of interest.

\section{FUNDING/SUPPORT}

This study was supported by the University Grants Commission of India (Award no. F.15-9 JULY 2016).2016(NET).

\section{DATA AVAILABILITY}

All data generated or analysed during the present study are available from the corresponding author on reasonable request.

\section{ETHICS APPROVAL}

The study was approved by the ethics committee of Indian Statistical Institute,

Kolkata, India (reference: ISI-IEC/2018/10/02). The patients were treated in accordance with the tenets of the Declaration of Helsinki. The patients provided written informed consent for all treatments and procedures.

\section{ACKNOWLEDGEMENTS}

We thank 'Itarai Asha Deep' and Dr. Ketaki Das, Public Health Research Officer, West Bengal Voluntary Health Association for organising the fieldwork. We are indebted to the Indian Statistical Institute, Kolkata (India) for logistic support.

\section{REFERENCES}

1. Dasgupta A, Pan T, Paul B, Bandopadhyay L, Mandal S. Quality of life of elderly people in a rural area of West Bengal: a communitybased study. Med J DY PatilVidyapeeth 2018;11:527-31. Crossref

2. United Nations. Department of Economic and Social Affairs, Population Division. World Population Ageing. https://www. un.org/en/development/desa/population/publications/pdf/ ageing/WorldPopulationAgeing2013.pdf. Accessed 29 October 2020.

3. United Nations. Department of Economic and Social Affairs, Population Division. World Population Prospects: The 2015 Revision, Key Findings and Advance Tables. https://population. un.org/wpp/publications/files/key_findings_wpp_2015.pdf. Accessed 29 October 2020.

4. Elderly in India-2016. Central Statistics Office. Ministry of Statistics and Programme Implementation. Government of India. http://mospi.nic.in/sites/default/files/publication_reports/ ElderlyinIndia_2016.pdf. Accessed 29 October 2020.

5. Mane AB. Ageing in India: some social challenges to elderly care. J Gerontol Geriatr Res 2016;5:e136. Crossref

6. Fried LP, Tangen CM, Walston J, et al. Frailty in older adults: evidence for a phenotype. J Gerontol A Biol Sci Med Sci 2001;56:M146-56. Crossref

7. Biritwum RB, Minicuci N, Yawson AE, et al. Prevalence of and factors associated with frailty and disability in older adults from China, Ghana, India, Mexico, Russia and South Africa. Maturitas 2016;91:8-18. Crossref

8. Chaudhary M, Arokiasamy P. Patterns of frailty and quality of life among older adults: comparative analysis using SAGE states of India. J Popul Ageing 2019;12:1-23.

9. Chen CY, Gan P, How CH. Approach to frailty in the elderly in primary care and the community. Singapore Med J 2018;59:2405. Crossref

10. Wilson D, Jackson T, Sapey E, Lord JM. Frailty and sarcopenia: the potential role of an aged immune system. Ageing Res Rev 2017;36:1-10. Crossref

11. Rosenberg IH. Summary comments of epidemiologic and methodologic problems in determining nutritional status of older persons. Proceedings of a conference. Albuquerque, New Mexico, October 19-21, 1988. Am J Clin Nutr 1989;50:12313. Crossref

12. Cruz-Jentoft AJ, Baeyens JP, Bauer JM, et al. Sarcopenia: European 
consensus on definition and diagnosis report of the European Working Group on Sarcopenia in Older People. Age Ageing 2010;39:412-23. Crossref

13. Tyrovolas S, Koyanagi A, Olaya B, et al. Factors associated with skeletal muscle mass, sarcopenia, and sarcopenic obesity in older adults: a multi-continent study. J Cachexia Sarcopenia Muscle 2016;7:312-21. Crossref

14. Mumu SJ, Ali L, Barnett A, Merom D. Validity of the global physical activity questionnaire (GPAQ) in Bangladesh. BMC Public Health 2017;17:650. Crossref

15. Chen LK, Liu LK, Woo J, et al. Sarcopenia in Asia: consensus report of the Asian Working Group for Sarcopenia. J Am Med Dir Assoc 2014;15:95-101. Crossref

16. Wen $X$, Wang $M$, Jiang CM, Zhang YM. Anthropometric equation for estimation of appendicular skeletal muscle mass in Chinese adults. Asia Pac J Clin Nutr 2011;20:551-6.

17. Kabir ZN, Herlitz A. The Bangla Adaptation of Mini-Mental State Examination (BAMSE): an instrument to assess cognitive function in illiterate and literate individuals. Int J Geriatr Psychiatry 2000;15:441-50. Crossref

18. Zimet GD, Dahlem NW, Zimet SG, Farley GK. The Multidimensional Scale of Perceived Social Support. J Pers Assess 1988;52:30-41. Crossref

19. Vellas B, Guigoz Y, Garry PJ, et al. The Mini Nutritional Assessment (MNA) and its use in grading the nutritional state of elderly patients. Nutrition 1999;15:116-22. Crossref

20. Frailty in Aging: Biological, Clinical and Social Implications. Theou O, Rockwood K, editors. Karger; 2015.

21. Kendhapedi KK, Devasenapathy N. Prevalence and factors associated with frailty among community-dwelling older people in rural Thanjavur district of South India: a cross-sectional study. BMJ open 2019;9:e032904. Crossref
22. Kojima G, Walters K, Iliffe S, TaniguchiY, Tamiya N. Marital status and risk of physical frailty: a systematic review and meta-analysis. J Am Med Dir Assoc 2020;21:322-30. Crossref

23. Brigola AG, Alexandre TDS, Inouye K, Yassuda MS, Pavarini SCI, Mioshi E. Limited formal education is strongly associated with lower cognitive status, functional disability and frailty status in older adults. Dement Neuropsychol 2019;13:216-24. Crossref

24. Fhon JR, Rodrigues RA, Neira WF, Huayta VM, Robazzi ML. Fall and its association with the frailty syndrome in the elderly: systematic review with meta-analysis. Rev Esc Enferm USP. 2016;50:1005-13. Crossref

25. Woo J, Ong S, Chan R, et al. Nutrition, sarcopenia and frailty: an Asian perspective. Transl Med Aging 2019;3:125-31. Crossref

26. Tamura $Y$, Ishikawa J, Fujiwara $Y$, et al. Prevalence of frailty, cognitive impairment, and sarcopenia in outpatients with cardiometabolic disease in a frailty clinic. BMC Geriatr 2018;18:264. Crossref

27. Buckinx F, Reginster JY, Brunois T, et al. Prevalence of sarcopenia in a population of nursing home residents according to their frailty status: results of the SENIOR cohort. J Musculoskelet Neuronal Interact 2017;17:209-17.

28. Gingrich A,Volkert D, Kiesswetter E, et al. Prevalence and overlap of sarcopenia, frailty, cachexia and malnutrition in older medical inpatients. BMC Geriatr 2019;19:120. Crossref

29. Nishiguchi S, Yamada M, Fukutani N, et al. Differential association of frailty with cognitive decline and sarcopenia in communitydwelling older adults. J Am Med Dir Assoc 2015;16:1204. Crossref

30. Davies B, García F, Ara I, Artalejo FR, Rodriguez-Mañas L, Walter S. Relationship between sarcopenia and frailty in the Toledo Study of Healthy Aging: a population based crosssectional study. J Am Med Dir Assoc 2018;19:282-6. Crossref 